\title{
Disquisiciones en torno al aborto
}

\section{Horacio Croxatto ${ }^{1}$}

Sin duda, este tema se puede enfocar desde el punto de vista biológico, filosófico, social, y legal sin que ninguno prevalezca sobre el otro. Pero enfocar el tema no es lo mismo que vivirlo. Al enfocarlo lo analizamos desde la distancia mientras que al vivirlo ponemos en juego el bienestar personal y nuestras tensiones sociales. Por ello, resulta muy valioso que este conjunto de contribuciones nos presente tanto los análisis de quienes han reflexionado sobre el tema así como las experiencias de quienes lo han vivido.

Es notable que la evolución de las especies condujera a la reproducción sexuada, y ello a su vez al establecimiento de dos clases de individuos, machos y hembras en cada especie. Más notable aún fue el establecimiento de la viviparidad característica de los mamíferos, con una distribución totalmente no equitativa y asimétrica de la responsabilidad biológica del embarazo, que recae exclusivamente en la hembra. Esto es visto como algo negativo por las mujeres que no quieren embarazarse y como un privilegio por aquellas que si desean experimentar la maternidad. Los hombres no perciben ni lo uno ni lo otro y esta diferencia entre los sexos ha determinado en la evolución cultural y social numerosas otras diferencias entre los géneros que tienden a favorecer el bienestar del hombre más que el de la mujer.

Desde un punto de vista biológico el embarazo es algo que le ocurre a la mujer no al embrión o al feto. Pero el aborto, aunque a veces se define como interrupción del embarazo, es también la interrupción del desarrollo de un nuevo individuo y por ende su muerte y es esto ultimo lo que causa la oposición al aborto entre quienes se oponen a él.

En la vida real la mujer que aborta voluntariamente lo hace procurando su bienestar, incluyendo en ello el bienestar de sus 
hijos ya nacidos. Lo hace estando conciente de sus necesidades, limitaciones, planes de vida, emociones, afectos, dignidad, etc., convencida de que no quiere o no puede asumir la responsabilidad integral de tener un hijo o hija en ese momento. Lo que significa para la mujer y lo que ella valora como bienestar es lo que hace del aborto un acto permisible para quienes se oponen a su penalización. En resumen, puede ser visto como un conflicto de intereses entre una persona hecha y derecha que sabe de su existencia y desea hacerla lo mejor posible y un individuo que se esta desarrollando en su vientre pero que todavía no sabe que existe, ni quiere nada y aún no es persona. Ni el embrión ni el feto tienen intereses comparables a los que tiene la madre. Algunas personas le atribuyen al embrión o al feto el derecho a la vida, pero el no se lo atribuye a si mismo, mientras que la mujer si se atribuye derechos a si misma. Hay una inmensa desproporción entre los amplios y numerosos derechos de la mujer y los de dudosa existencia del embrión, lo cual justifica que prevalezca el derecho de la mujer a ejercer autonomía en la decisión de proseguir con su embarazo o interrumpirlo. Las consecuencias de morir a una edad $u$ otra son irrelevantes para un individuo que se está desarrollando pero que no sabe que existe mientras son cruciales para una mujer que tiene conciencia y vocación por su vida. En el aborto hay un bien -el bienestar de la madre y sus hijos ya nacidos- y un mal -la muerte del feto- pero el bien supera ampliamente la magnitud del mal y por lo tanto el aborto es un mal menor. Los riesgos para la madre asociados al aborto no se consideran aquí en la valoración así como tampoco los riesgos asociados al embarazo por cuanto no es cuestionable que cada persona asuma los riesgos asociados a diversas actividades tales como deportes, tomar alcohol, ser bombero, fumar, o salir a la calle.

Casi todas las reflexiones sobre el aborto están centradas en lo que le pasa al embrión. El embrión se muere, deja de existir y en nuestra cultura la muerte es considerada lo peor que le puede pasar a un ser vivo, a pesar de la instalada creencia de que se traslada a vivir al lado de Dios y a gozar por la eternidad de su compañía. Pero con la muerte cesa de operar la conciencia de existir, de ser yo, de sentir, de querer etc., es un paso a la nada misma y por lo tanto el que esta muerto no esta ni gozando ni 
tampoco sufriendo. Cuando muere el embrión, lo que pierde o deja de ganar, es su potencialidad de llegar a ser persona y disfrutar de esa condición.

Pocas veces la reflexión se centra en lo que le pasa a la mujer si aborta o si se ve obligada a seguir adelante con su embarazo. Aquí nuevamente dejamos fuera de la reflexión los riesgos vitales o de morbilidad en uno y otro caso, así como el embarazo resultante de una violación, no porque no sean importantes, sino porque corresponden a otra categoría valórica. Las vivencias relatadas en esta compilación de Nomadías son tal vez más lucidas que cualquier argumento. La mujer sufre, se siente en una encrucijada, le es difícil tomar la decisión de abortar, ninguna lo quiere pero lo que significa para ella seguir adelante con ese embarazo y dar a luz y tener que criar un bebe y luego hacerse responsable de cuidarlo, alimentarlo, educarlo, y darle bienestar hasta que alcance la mayoría de edad, muchas veces sin la contribución del padre, además de las implicancias sociales, y las consecuencias negativas para sus planes de vida no es tolerable y se ve forzada a detener lo que percibe como una poderosa amenaza a su bienestar.

Es indudable que toda valoración del aborto tiene que poner necesariamente en la balanza tanto los derechos del embrión como los de la madre y lo que le pasa a uno y otro si aborta o no aborta. No es armónico con la razón valorar solamente los derechos del embrión y lo que le pasa al embrión y excluir los derechos de la mujer y lo que le pasa a ella.

Suele escucharse que la mujer no tiene derecho a quitarle la vida al embrión. Este "principio" rara vez se discute o se analiza pues se entiende a priori que es un caso particular de un principio más general que dice que nadie tiene el derecho de quitarle la vida a nadie. Este es universalmente aceptado pues procura la convivencia entre los seres humanos aun en condiciones de máxima discrepancia de intereses, algo esencial para garantizar la sobrevivencia de una sociedad compuesta por grupos donde la diversidad es un atributo universal. No obstante la misma sociedad que enarbola este principio acepta la guerra que conduce a la muerte a millares de personas muchas veces con consecuencias devastadoras para los pueblos involucrados. Contrariamen- 
te, quitarle la vida a un embrión no afecta ni en lo más mínimo la sobrevivencia de la sociedad, ni daña a persona ni pueblo alguno, por lo que la extensión del principio universalmente aceptado al caso particular del embrión no tiene una racionalidad obvia. Más aun pone en abierta contradicción lo que se dice con lo que se hace.

¿Tiene el embrión derecho a demandar de la mujer que lo acoja en su seno materno? Si no es persona, ¿tiene derecho a exigir algo de las personas?

El relato de las vivencias nos enseña claramente que ninguna de las dos opciones, interrumpir el embarazo o continuarlo, es percibida como buena por la mente ni por el corazón. Todo tiene excepciones, pero en la gran mayoría de los casos la situación es extremadamente conflictiva, la mujer no quiere ni lo uno ni lo otro pero tiene que decidirse por una de las dos opciones. Y esta claro que nadie puede ni tiene derecho a hacerlo por ella. Tiene que hacer uso de su autonomía y ello debe ser respetado. El gran aporte que puede hacer la sociedad al problema es ofrecerle a la mujer consejería y toda clase de apoyo a corto y largo plazo si opta por continuar con su embarazo así como también ofrecerle las mejores condiciones sanitarias y consejería para evitar un nuevo embarazo si su decisión es interrumpirlo. Otra cosa que la sociedad tiene que abordar es valorar la responsabilidad que le cabe al hombre en la problemática que enfrenta la mujer embarazada y legislar de acuerdo a sus conclusiones.

\section{Nota}

1 Médico y ex director de ICMER. 